\title{
One-step oxidehydration of glycerol to acrylic acid using ETS-10-like vanadosilicates
}

\author{
Alex Silva Paula a, Luiz Gustavo Possato ${ }^{\mathrm{b}}$, Davi Rubinho Ratero a , Janine Contro a, \\ Keren Keinan-Adamsky ${ }^{c}$, Ricardo Reis Soares ${ }^{\mathrm{d}}$, Gil Goobes ${ }^{\mathrm{c}}$, Leandro Martins ${ }^{\text {b }}$, \\ José G. Nery ${ }^{\text {a, * }}$ \\ a Department of Physics, IBILCE, State University of São Paulo - UNESP, São José do Rio Preto, Brazil \\ ${ }^{\mathrm{b}}$ Institute of Chemistry, State University of São Paulo - UNESP, Araraquara, Brazil \\ c Department of Chemistry, Bar-Ilan University, Ramat Gan 52900, Israel \\ d Federal University of Uberlândia, Uberlândia, Brazil
}

\section{A R T I C L E I N F O}

\section{Article history:}

Received 23 December 2015

Received in revised form

6 May 2016

Accepted 12 May 2016

Available online 22 May 2016

\section{Keywords:}

Vanadosilicates

Glycerol

Oxidehydration reactions

Acrylic acid

Mars-van Krevelen mechanism

\begin{abstract}
A B S T R A C T
Vanadosilicates isostructural to ETS-10 and AM-6 microporous materials were synthesized hydrothermally using derivatives of cis- and trans-3,5-dimethyl-piperidine as organic structure directing agents (SDAs) and were subsequently tested as heterogeneous catalysts for the oxidehydration of glycerol to acrylic acid. The best performances were obtained with vanadosilicates prepared with 1,1,3,5-tetramethyl piperidinum cations, which were capable of converting $93.6 \%$ of glycerol to acrylic acid in one step, with 85.4\% selectivity. Other important chemicals such as acrolein (3.8\%), propanal (2.3\%), acetaldehyde (3.2\%), acetic acid (2.5\%), and propionic acid (1.4\%) were produced in smaller amounts. The results clearly indicated that these vanadosilicates are potential multifunctional catalysts capable of performing the oxidehydration of glycerol to acrylic acid in a single step. Spectroscopic data obtained from ${ }^{51}$ VMASNMR, UV-Vis, XPS, and Raman scattering analyses suggested that the selectivity of these vanadosilicates for the oxidative dehydration of glycerol to acrylic acid could be attributed to the capacity of the vanadium species for dynamic adoption of multiple oxidation states during the catalytic reaction.
\end{abstract}

(c) 2016 Elsevier Inc. All rights reserved.

\section{Introduction}

High purity glycerol is an important industrial feedstock that has applications in the food, cosmetics, and pharmaceutical industries, amongst others. However, it is expensive to refine crude glycerol, especially in medium-sized or small plants. Research in both academic and industrial laboratories has therefore focused on the development of innovative processes for the conversion of pure and crude glycerol into valuable products. Glycerol is considered one of the top twelve building block chemicals that can be derived from carbohydrates and converted to valuable commodity chemicals such as glyceric acid, propylene glycol, 1,3- and 1,2propanediol, branched polyesters, and polyols [1]. These chemicals can be formed using different routes including selective oxidation, hydrogenolysis, dehydration, transesterification,

\footnotetext{
* Corresponding author.

E-mail address: nery@ibilce.unesp.br (J.G. Nery).
}

etherification, oligomerization, and polymerization, as reviewed elsewhere [2,3]. Glycerol oxidation or reduction is achieved by means of a complex pathway of reactions that can lead to a large number of useful intermediate substances or value-added chemicals (Scheme 1).

Acrylic acid is one of the many value-added molecules prepared by the catalytic conversion of glycerol. This molecule is attractive from economic and environmental perspectives, and is used in a number of industrial applications. The primary use of acrylic acid, accounting for approximately $67 \%$ of the total production, is as a raw material for the manufacture of acrylic esters and resins used in coatings and adhesives. Currently, more than 3 million tons per year of acrylic acid are produced by the petrochemical industry using the two-step gas-phase oxidation of propylene [4]. Hence, it is highly desirable to be able to synthesize acrylic acid by means of an integrated renewable route that minimizes the use of petrochemical resources as raw materials.

Heterogeneous catalysts based on vanadium oxides are well known as active and selective oxidation catalysts, due to their 


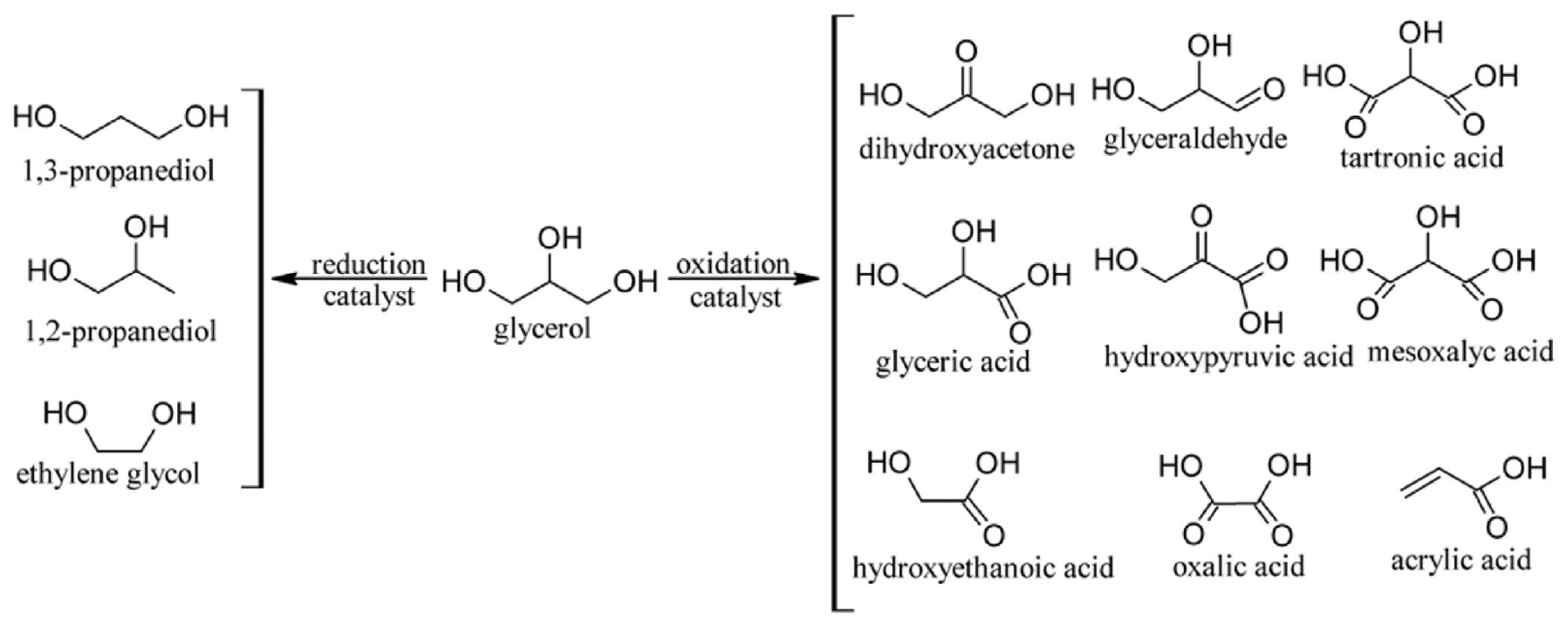

Scheme 1. Value-added products obtained from the oxydation and reduction of glycerol.

capacity to adopt multiple oxidation states and the ability to achieve dynamic changes in vanadium oxidation states during catalytic reaction according to the Mars-van Krevelen mechanism [5]. There have been several investigations of efficient multifunctional catalysts capable of performing the oxidehydration of glycerol in a single step [6-9]. López Nieto et al. [10,11] described the use of vanadium pyrophosphate for this reaction, while Ueda et al. [8] studied different transition metal oxides [oxides, V/W mixed oxides with hexagonal tungsten bronze structure, and $\mathrm{V} / \mathrm{W} / \mathrm{Nb}$ mixed oxides]. Until now, the best result was the conversion of $100 \%$ of glycerol into $50 \%$ of acrylic acid using $\mathrm{V}-\mathrm{W}-\mathrm{Nb}$ mixed oxides [10].

Several factors can play a role in the selective oxidation achieved by heterogeneous catalysts based on vanadium oxides. These include: (a) vanadium lattice oxygen, (b) vanadium-oxygen bond strength, (c) host structure and the ordering and environment of oxygen atoms, (d) dynamic redox cycles between multiple oxidation states of the metal, (e) multi-functionality of the active sites, (6) spatial isolation of active sites, and (f) phase cooperation. The $\mathrm{V}-\mathrm{Mo}-\mathrm{Te}-\mathrm{Nb}$ oxides are good examples of catalysts that present all these properties [8].

The use of zeolite-based catalysts containing vanadium with the specific aim of producing value-added products using glycerol as raw material has not been widely reported in the literature. The first study was published in 2013, describing the production of acrylic acid by glycerol oxidehydration using vanadium impregnated on an acid zeolite with BEA topology [12], although only a few aspects of catalyst performance were explored. In 2015, Martins et al. [13] reported the catalytic behavior of bifunctional $\mathrm{V}_{2} \mathrm{O}_{5}$ / MFI catalysts with acidic and oxidizing properties for the gas-phase oxidehydration of glycerol. One of the main reaction products was acrylic acid, formed by dehydration of glycerol to acrolein at an acidic site and subsequent oxidation at a redox site, but the selectivity of the reaction was very low (17\%). Hunsom et al. [14] reported the one-pot oxidehydration of glycerol to value-added compounds using metal-doped SiW/HZSM5-5, with 99.7\% conversion and $36.23 \%$ selectivity to acrylic acid. Mairelles-Torres et al. [15]described the dehydration of glycerol to acrolein using solid vanadium-phosphorus catalysts on supported on a mesoporous zirconium SBA-15 silica. However, no direct conversion of glycerol to acrylic acid was observed and the selectivity to acrolein was around 40\%.Therefore, apart from zeolites of the BEA and MFI families, no other zeolites impregnated with vanadium oxides have been reported as being capable of performing one-pot catalytic conversion of glycerol to acrylic acid.

AM-6 is a large-pore vanadosilicate containing hexacoordinated vanadium, whose structure is similar to that of the ETS-10 titanosilicate. It was first reported by Rocha et al. [16], who synthesized it in the presence of ETS-10 seeds [16]. The synthesis of AM- 6 in the absence of seeds, but using structure directing agents (SDAs) such as TMAOH and chiral organic molecules derived from decahydroquinoline, 2,6-dimethyl-piperidine, 3,5-dimethylpiperidine, and (S)-sparteine has been reported by Sacco et al. [17] and Paula et al. [18].

AM-6 vanadosilicate catalysts have been employed as heterogeneous catalysts for the highly selective dehydration of t-butanol to isobutene [19], as a solid support for enzyme immobilization in transesterification reactions [20], and for the photocatalytic oxidation of ethylene [21]. However, they have not yet been used specifically for the catalytic oxidehydration of glycerol to valueadded products (Scheme 1). In a previous study, investigation was made of microporous vanadosilicate ETS-10-like materials produced using different organic templates derived from piperidinium cations [18]. Systematic catalytic studies were performed with the aim of identifying their possible applications as heterogeneous catalysts for the production of biofuels and value-added products derived from glycerol. Here, we present the best catalytic results obtained with vanadosilicate catalysts prepared using 1,1,3,5-tetramethyl-piperidinium cation derivatives.

\section{Experimental section}

\subsection{Synthesis of organic templates derived from 3,5-cis-trans-} dimethylpiperidine

Scheme 2 shows a schematic illustration of the SDAs synthesized using the following procedure. One mol of 3,5dimethylpiperidine (Aldrich, mixture of isomers) and $1.5 \mathrm{~mol}$ of base (potassium bicarbonate) were added to $170 \mathrm{~mL}$ of methanol. Dropwise addition was made of $1 \mathrm{~mol}$ of the alkyl dihalide or $2 \mathrm{~mol}$ of the halide to the solution over a $10-15$ min period, followed by refluxing for $48 \mathrm{~h}$. The reaction mixture was cooled to room temperature and the methanol was evaporated. The white solid remaining was extracted with $250 \mathrm{~mL}$ of chloroform and the precipitated solid was filtered. The chloroform fraction was 


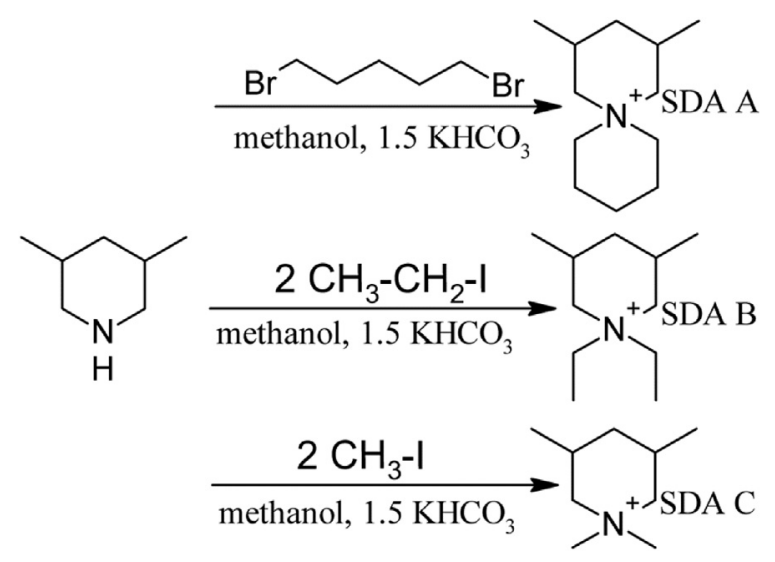

Scheme 2. Syntheses of organic templates used as structure directing agent in the syntheses of vanadosilicates.

evaporated under vacuum and the solids were recrystallized with hot isopropanol and cold acetone.

\subsubsection{Synthesis of the catalysts}

The synthesis of catalyst A was performed in Teflon-lined autoclaves under static hydrothermal conditions. In a typical synthesis, $10.87 \mathrm{~g}$ of water, $3.64 \mathrm{~g}$ of sodium silicate ( $26 \mathrm{wt} \%$ of $\mathrm{SiO}_{2}$ ), $0.411 \mathrm{~g}$ of sodium hydroxide, $1.08 \mathrm{~g}$ of potassium fluoride, and $1.75 \mathrm{~g}$ of 2,4,-dimethyl-6-azoniaspiro [5.5] undecane were mixed together. A second solution was made by dissolving $1.14 \mathrm{~g}$ of vanadyl sulfate in $2.5 \mathrm{~g}$ of water. These two solutions were combined and stirred for $1 \mathrm{~h}$. The final gel composition was $0.97 \mathrm{SiO}_{2}: 0.2$ SDA:0.1 $\mathrm{V}_{2} \mathrm{O}_{5}: 1$ $\mathrm{Na}_{2} \mathrm{O}: 0.23 \mathrm{~K}_{2} \mathrm{O}: 30 \mathrm{H}_{2} \mathrm{O}$. The gel was then heated in an autoclave under autogenous pressure for 7 days at $200{ }^{\circ} \mathrm{C}$. After the hydrothermal syntheses, the crystalline powder products were filtered, washed with water, dried at room temperature overnight, and calcined at $300{ }^{\circ} \mathrm{C}$ for $6 \mathrm{~h}$ to eliminate the organic template. The vanadosilicates were then submitted to ion exchange procedures by adding $1 \mathrm{~g}$ of sample to $30 \mathrm{~mL}$ of $0.5 \mathrm{~mol} \mathrm{~L}^{-1}$ ammonium chloride solution and stirring for $18 \mathrm{~h}$ at $80^{\circ} \mathrm{C}$. The samples were again calcined at $300{ }^{\circ} \mathrm{C}$ for $6 \mathrm{~h}$. The catalysts $\mathrm{B}$ and $\mathrm{C}$ were prepared hydrothermally using the same synthesis procedure described for catalyst A, but using SDA B (1.765 g) and SDA C (1.820 g), respectively.

\subsection{Physicochemical characterization of the vanadosilicates}

All the polycrystalline samples were characterized by XRD using a Rigaku Multiflex instrument operated at $30 \mathrm{kV}$ and $15 \mathrm{~mA}$, with Ni-filtered Cu-Ka radiation $(\lambda=1.5418 \AA$ ). The X-ray analyses were performed using $2 \theta$ angles from 3 to $80^{\circ}$ and a goniometer rate of $0.5^{\circ}(2 \theta) \mathrm{min}^{-1}$.

Raman and infrared absorption (FT-IR) spectra of the vanadosilicates were collected at room temperature using RFS 100 and Equinox 55 instruments, respectively (Bruker, Germany). Ultraviolet-visible (UV-Vis) spectra were obtained using a Lambda $1050 \mathrm{UV} /$ Vis/NIR spectrometer (Perkin-Elmer) coupled to a $150 \mathrm{~mm}$ integrating sphere. A $1064 \mathrm{~nm} \mathrm{Nd:YAG} \mathrm{laser} \mathrm{operated} \mathrm{at} 90 \mathrm{~mW}$ was used as excitation source in the Raman measurements. The FTIR spectra were collected using $\mathrm{KBr}$ pellets, in the range $500-4000 \mathrm{~cm}^{-1}$, at a resolution of $4 \mathrm{~cm}^{-1}$ and an interval of $1 \mathrm{~cm}^{-1}$ and each spectrum was averaged over 256 scans.

Thermal analyses of the materials were performed using a Netzsch 429 instrument. The as-synthesized samples $(5 \mathrm{mg})$ were heated in a stream of synthetic air $(50 \mathrm{~mL} \mathrm{~min}-1)$ at $10{ }^{\circ} \mathrm{C} \mathrm{min}^{-1}$ in the temperature range $25-1000{ }^{\circ} \mathrm{C}$.

The acidity of the calcined catalysts was determined by temperature programmed desorption of ammonia (TPD-NH $\mathrm{N}_{3}$ ). Previously, $200 \mathrm{mg}$ of sample was degassed at $300{ }^{\circ} \mathrm{C}$ for $1 \mathrm{~h}$ under a $60 \mathrm{~mL} \mathrm{~min}^{-1}$ flow of helium. The temperature was then decreased to $100{ }^{\circ} \mathrm{C}$ and the sample was exposed to a flow of $1 \%$ ammonia in helium $\left(60 \mathrm{~mL} \mathrm{~min}^{-1}\right)$ for $1 \mathrm{~h}$. After surface saturation, the sample was submitted to helium treatment at $100{ }^{\circ} \mathrm{C}$ for $1 \mathrm{~h}$ to remove physisorbed ammonia. The TPD- $\mathrm{NH}_{3}$ analysis was performed between 100 and $500{ }^{\circ} \mathrm{C}\left(\right.$ at $10^{\circ} \mathrm{C} \mathrm{min}^{-1}$ ), using a $60 \mathrm{~mL} \mathrm{~min}^{-1}$ flow of helium. The desorbed ammonia was monitored and quantified using a Pfeiffer vacuum mass spectrometer coupled to the outlet stream of the tubular reactor.

Solid-state magic angle spinning (MAS) NMR spectra were acquired with a Bruker Avance ${ }^{\text {III }}$ NMR spectrometer operated at $11.74 \mathrm{~T}$ field strength, using a $4 \mathrm{~mm}$ double resonance MAS probe. The vanadosilicate samples ( $45 \mathrm{mg}$ ) were packed into a zirconia rotor with Kel-F caps and were spun at $10-13 \mathrm{kHz}$ at room temperature. Lorentzian line broadening of $30 \mathrm{~Hz}$ was applied to all the NMR data. ${ }^{29} \mathrm{Si}$ MAS NMR spectra were acquired at a spinning rate of $8 \mathrm{kHz}$, with $90^{\circ}$ pulse width of $3 \mu \mathrm{s}$, delay time of $3 \mathrm{~s}, 20000$ scans, 2048 data points, and spectral width of $100 \mathrm{kHz} .{ }^{51} \mathrm{~V}$ MAS NMR spectra were acquired at a spinning rate of $14 \mathrm{kHz}$, with a short onresonance single-pulse excitation of $1.5 \mu \mathrm{s}$, delay time of $0.5 \mathrm{~s}$, 16000 scans, 4000 data points, and spectral width of $800 \mathrm{kHz}$. The ${ }^{29} \mathrm{Si}$ chemical shifts were referenced to 4,4-dimethyl-4silapentane-1-sulfonic acid (DSS) at $1.457 \mathrm{ppm}$, and the ${ }^{51} \mathrm{~V}$ chemical shifts were referenced to $\mathrm{VOCl}_{3}$ and to sodium orthovanadate $\left(\mathrm{Na}_{3} \mathrm{VO}_{4}\right)$ at $-545 \mathrm{ppm}$ as a secondary reference material.

X-ray photoelectron spectroscopy (XPS) analyses were performed using a UNI-SPECS UHV spectrometer, with the base pressure below $5 \times 10^{-7} \mathrm{~Pa}$. The $\mathrm{Al} \mathrm{K}$ line was used $(1486.6 \mathrm{eV})$ and the analyzer pass energy was set to $10 \mathrm{eV}$. The binding energies of the $\mathrm{V}$ $2 \mathrm{p} 3 / 2$ core level spectra were corrected using the hydrocarbon component of adventitious carbon fixed at $285.0 \mathrm{eV}$. The deconvoluted spectra were obtained using multiple Voigt profiles, without placing constraints. The width at half maximum (FWHM) varied between 0.9 and $2.0 \mathrm{eV}$, and the accuracy of the peak positions was $\pm 0.1 \mathrm{eV}$.

\subsection{Catalytic tests using the vanadosilicates}

The oxidative dehydration of glycerol was carried out in the gas phase at $320^{\circ} \mathrm{C}$ using $150 \mathrm{mg}$ of catalyst placed in a continuousflow glass fixed-bed reactor. The gas flow was kept at $30 \mathrm{~mL} \mathrm{~min}^{-1}$ and its composition was varied from pure $\mathrm{N}_{2}$ or $\mathrm{O}_{2}$ to a mixture of $\mathrm{O}_{2}(20 \%)$ and $\mathrm{N}_{2}(80 \%)$. The catalysts were previously heated to $320^{\circ} \mathrm{C}$ under a $30 \mathrm{~mL} \mathrm{~min}^{-1}$ flow of nitrogen and kept at this temperature for $15 \mathrm{~min}$. Subsequently, a glycerol solution (10 wt\% in water) was added at a flow rate of $0.05 \mathrm{~mL} \mathrm{~min}^{-1}$, using a continuous syringe pump (KD Scientific). Nitrogen at a flow rate of $30 \mathrm{~mL} \mathrm{~min}{ }^{-1}$ was used as a carrier gas to ensure a homogeneous flow of glycerol through the catalytic bed. The products were collected in a gas-liquid separator kept at $1{ }^{\circ} \mathrm{C}$ and analyzed using a gas chromatograph (GC-2014, Shimadzu) equipped with a capillary column (Rtx-1, $30 \mathrm{~m}, 0.32 \mathrm{~mm}, 1 \mu \mathrm{m}$ ) and an FID detector.

The products exiting the reactor were quantified by weighing the material condensed at $1{ }^{\circ} \mathrm{C}$ during $1 \mathrm{~h}$ in the gas-liquid separator. The accuracy of the quantification was confirmed using nbutanol as an internal standard and comparison with the calibration curves. The analyses were performed in triplicate and the retention times were compared with those of authentic compounds. The conversion of glycerol ( $\left.\mathrm{X}_{\text {glycerol }}\right)$ [22] and product selectivity (S) were calculated according to Eqs. (1) and (2), 
respectively. The carbon balance (between 0 and 1 ) was calculated from the condensed products flowing out of the reactor, according to Eq. (3).

$X_{\text {glycerol }}(\%)=\frac{{ }^{n} G l^{\text {input }}-{ }^{n} G l^{\text {output }}}{{ }^{n} G l^{\text {input }}} \times 100$

$S(\%)=\frac{n_{i}}{{ }^{n} l^{\text {linput }}-{ }^{n} \text { loutput }^{\text {out }}} \times \frac{Z i}{{ }^{Z} G l} \times 100$

Carbon balance $=\frac{\text { mol of carbon in the liquid products }}{\text { mol of carbon in the converted glycerol }}$

where ${ }^{n} G l^{\text {input }}$ and ${ }^{n} G l^{\text {output }}$ are the molar flows of glycerol in the input and output ( $\mathrm{mol} \mathrm{min}{ }^{-1}$ ), respectively; $n_{i}$ is the molar flow of products $\left(\mathrm{mol} \mathrm{min}^{-1}\right.$ ); and $Z_{G l}=3$ and $Z_{i}$ are the stoichiometry coefficients corresponding to the number of carbon atoms in a molecule of glycerol and in the products, respectively.

\section{Results and discussion}

\subsection{Structural characterization of the catalysts}

Fig. 1 shows the morphology of the vanadosilicates prepared with the SDAs derived from 3,5-dimethylpiperidine. The vanadosilicates were composed of thick plate-like crystals with truncated bipyramidal shapes and accentuated faulting on the sides. XRD analyses of these materials were performed before and after the catalytic reactions. Prior to the catalytic tests, all the vanadosilicates presented similar XRD patterns (Fig. 2), while partial collapse of the structures was observed after the oxidehydration of glycerol at $320^{\circ} \mathrm{C}$. Rocha et al. $[16,23]$ observed that calcination of the AM-6, $\mathrm{AM}-13$, and AM-14 vanadosilicates in air or oxygen at $400{ }^{\circ} \mathrm{C}$ caused partial collapse of the crystallographic structures of these materials, and that the vanadosilicates were completely amorphous at $450{ }^{\circ} \mathrm{C}$. Here, the XRD results for the catalysts treated in atmospheres of pure $\mathrm{N}_{2}$, pure $\mathrm{O}_{2}$, and a mixture of $\mathrm{O}_{2}(20 \%)$ and $\mathrm{N}_{2}(80 \%)$ showed that the catalysts remained structurally stable in a pure $\mathrm{N}_{2}$ atmosphere (Supplementary Material), while the presence of $\mathrm{O}_{2}$ led to structural collapse of the catalysts. Hence, the structural collapse was caused not only by the thermal treatment, but also by the presence of oxygen. This observation suggests that at different steps of the catalytic conversion of glycerol to acrylic acid, intermediate species could have been formed that were detrimental to the original vanadosilicate structures.

Although the XRD data revealed similar crystallographic structures for all the vanadosilicates prepared with the 3,5dimethylpiperidine derivatives, their ${ }^{29} \mathrm{Si}$ and ${ }^{51} \mathrm{~V}$ MAS NMR spectra showed some significant differences. For all the catalysts (A, $\mathrm{B}$, and $\mathrm{C}$ ), the ${ }^{29} \mathrm{Si}$ MAS NMR spectra (Fig. 3) showed a common dominant line centered at $-93.5 \mathrm{ppm}$, together with an unresolved shoulder line. The main peak was assigned to a tetrahedral $\mathrm{Si}(3 \mathrm{Si}, 1$ V) species bonded to an octahedral $V$ species that was unaffected by paramagnetic $\mathrm{V}^{4+}$ ions. This assignment was based on structural similarity to an ETS-like vanadosilicate reported previously [16], with the ${ }^{29} \mathrm{Si}$ MAS NMR data showing $\mathrm{Si}(3 \mathrm{Si}, 1 \mathrm{~V})$ species at -87 to $-97 \mathrm{ppm}$ and (4Si, $0 \mathrm{~V}$ ) species at $-109 \mathrm{ppm}$. Deconvolution of the
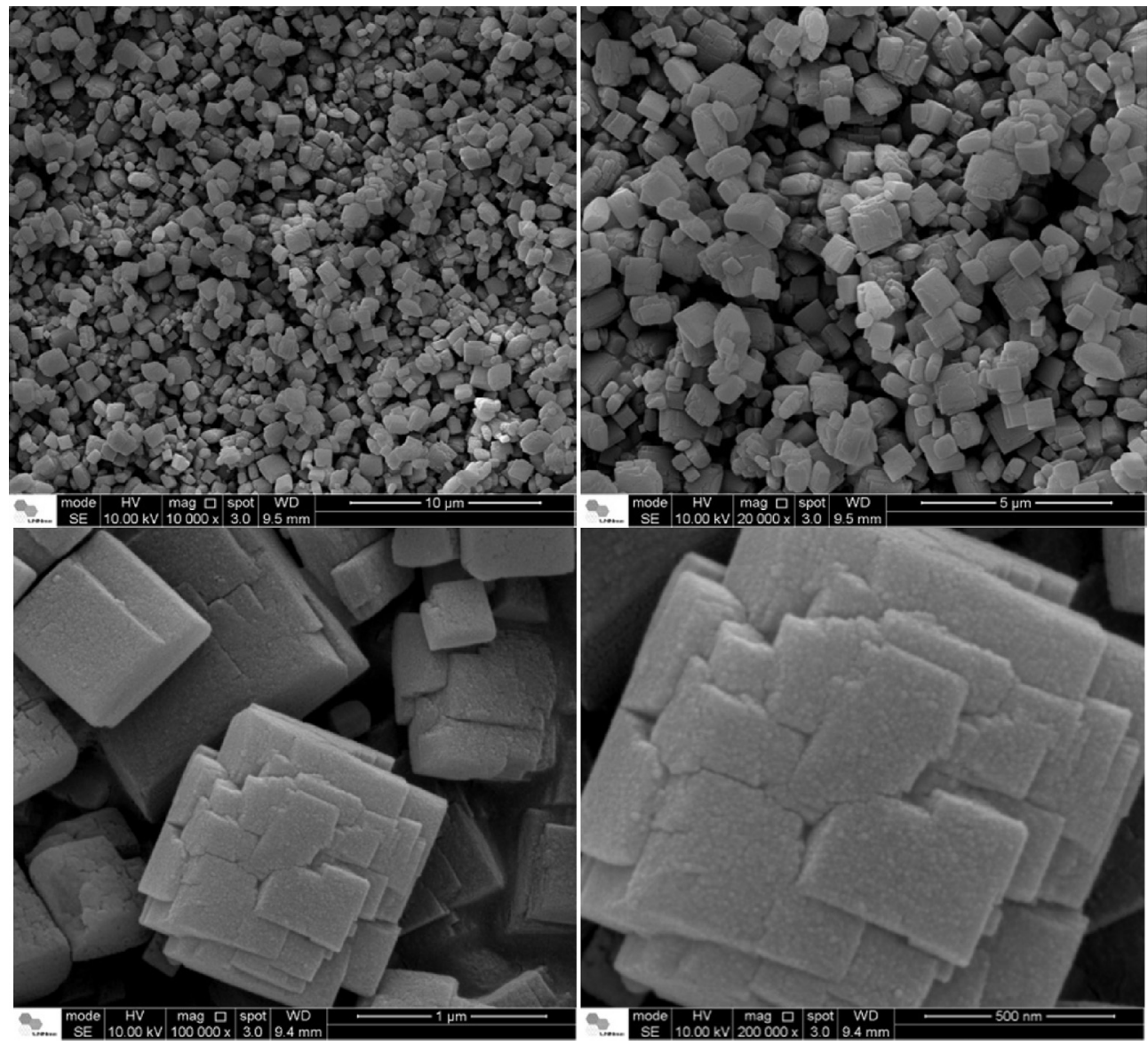

Fig. 1. SEM images of vanadosilicate prepared in the presence of 1,1,3,5-tetramethylpiperdinium cation (catalyst C). 

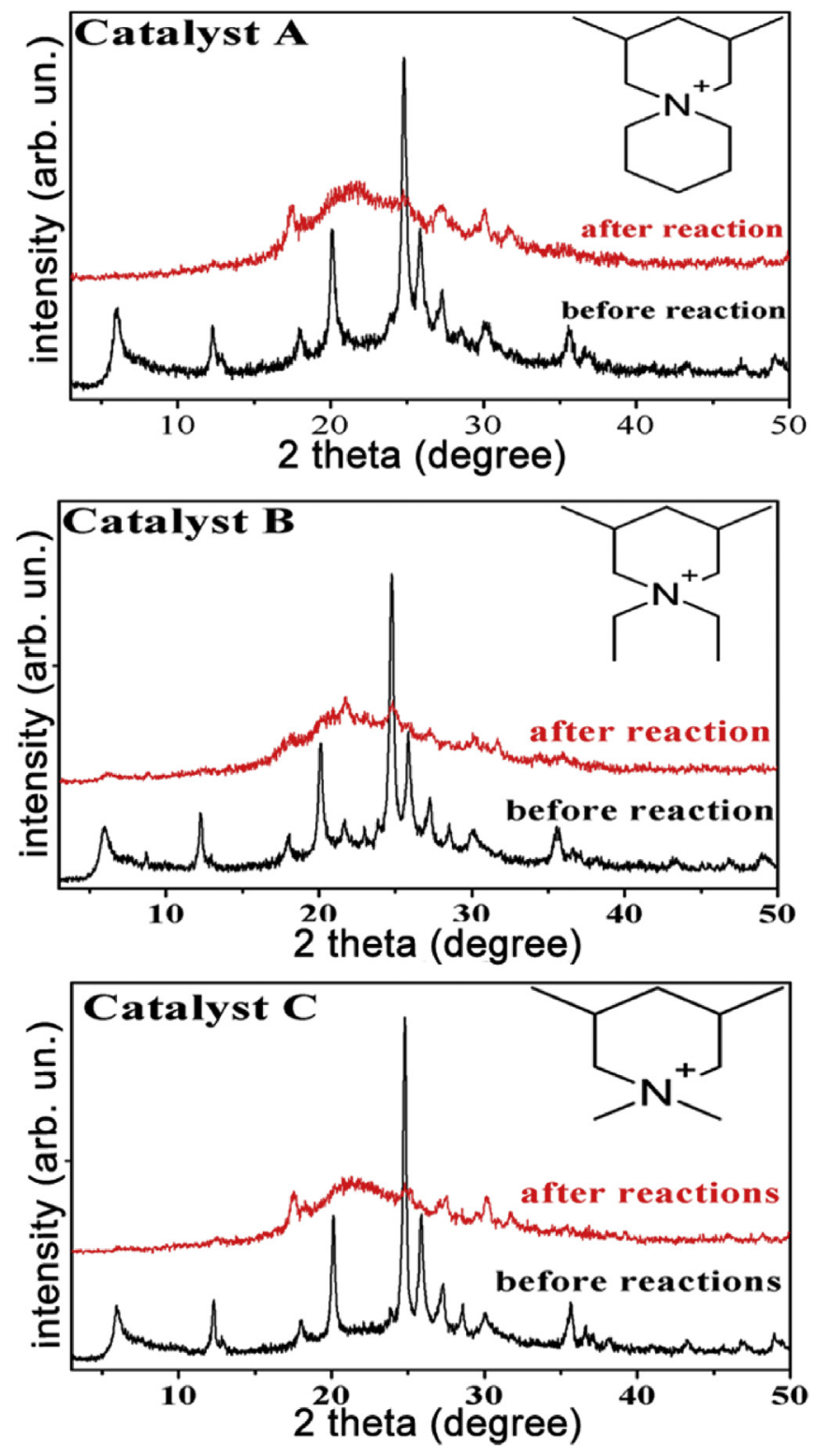

Fig. 2. XRD patterns of the vanadosilicates prepared with the organic templates derived from 3,5-dimethylpiperidinium cations.

shoulder line (data not shown) revealed a line at $-91.5 \mathrm{ppm}$ that was two-fold broader than the main line. This line matched a $\mathrm{Si}(3 \mathrm{Si}$, $1 \mathrm{~V})$ species with octahedral $\mathrm{V}$ ion [16], broadened by a

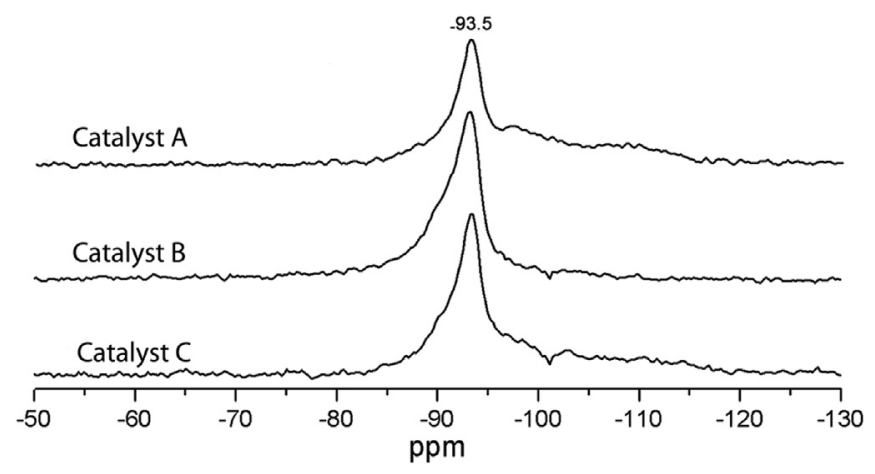

Fig. 3. ${ }^{29} \mathrm{Si}$-MAS-NMR spectra of the vanadosilicates. neighbouring $\mathrm{V}^{4+}$ ion, and represented about $45 \%, 39 \%$, and $38 \%$ of all the observable $\mathrm{Si}$ sites in catalysts $\mathrm{A}, \mathrm{B}$, and C, respectively. Si species related to the $\mathrm{Si}(4 \mathrm{Si}, 0 \mathrm{~V}$ ) environment (without close $\mathrm{V}$ neighbors) were not observed here $[16,23]$. The ${ }^{29} \mathrm{Si}$ MAS NMR results therefore confirmed vanadium occupation of the available octahedral sites in the crystallographic framework, which was responsible for the catalytic efficiency of these vanadosilicate materials.

Further information concerning the $\mathrm{V}$ species in the framework was provided by the ${ }^{51} \mathrm{~V}$ MAS NMR measurements (Fig. 4). The observed resonance lines could be related to different vanadium oxidation states resulting from the complex and rich chemistry of the material. Previous studies of vanadosilicates have indicated that $\mathrm{V}^{4+}$ and $\mathrm{V}^{5+}$ ions can both be present in these materials, but the presence of paramagnetic $\mathrm{V}^{4+}$ species can make the $\mathrm{V}^{5+}$ signal too broad to be detectable. The ${ }^{51} \mathrm{~V}$ MAS NMR spectra of catalysts A, B, and $C$ showed a common resonance line located at $-565 \mathrm{ppm}$. Two distinguishable resonance lines at $-610 \mathrm{ppm}$ and $-597 \mathrm{ppm}$ were also observed for catalysts A and C, respectively. All the lines could be assigned to distorted tetrahedral vanadium sites with oxidation states corresponding to $\mathrm{V}^{5+}$ species $[18,24,25]$. For example, the narrower $-565 \mathrm{ppm}$ line was previously attributed to $\mathrm{V}_{2} \mathrm{O}_{7}^{4-}$ $[26,27]$. The ${ }^{51} \mathrm{~V}$ MAS NMR spectrum of catalyst $\mathrm{B}$ contained two peaks at -480 and -565 ppm that were significantly broader than the peaks in the spectra of the other two catalysts, indicating the presence of adjacent paramagnetic $\mathrm{V}^{4+}$ species. It has been reported previously that the $\delta_{22}$ chemical shift component of distorted tetrahedral $\mathrm{V}$ species appears between -450 and $-550 \mathrm{ppm}$, so these lines could represent such species [16]. Since the resonance frequencies of lines in half-integer spin nuclei MAS NMR spectra with large quadrupolar couplings are sums of chemical shifts and second order quadrupole isotropic shifts, it is necessary to have accurate knowledge of the coupling interactions, or perform measurements using techniques such as 2D MQMAS, in order to be able to extract accurate chemical shift values.

Raman and DR UV-vis spectroscopy data can also provide useful complementary information concerning $\mathrm{V}^{4+}$ and $\mathrm{V}^{5+}$ species present in the samples. The Raman scattering data (Fig. 5) also showed strong evidence of the incorporation of vanadium into the crystalline structure. The spectra for catalysts A, B, and C presented strong and sharp bands centered at around $860 \mathrm{~cm}^{-1}$, which could be attributed to relatively undistorted $\mathrm{VO}_{6}$ octahedra present in the structures of the materials [16]. A low intensity band centered at $1025 \mathrm{~cm}^{-1}$ was also observed in the spectra for catalysts B and C, which could be ascribed to the short terminal $\mathrm{V}=\mathrm{O}$ bonds of defect

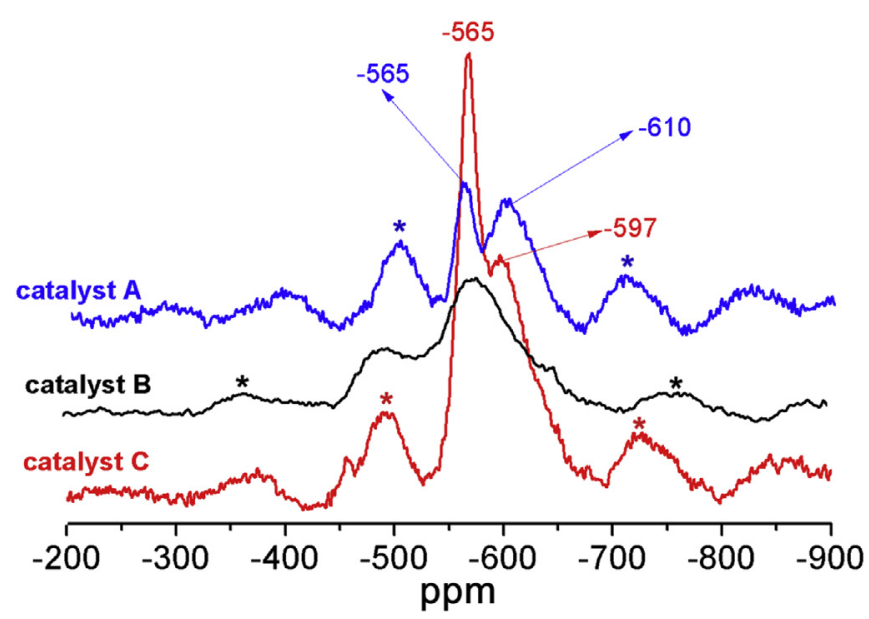

Fig. 4. ${ }^{51} \mathrm{~V}$ MAS-NMR of the catalysts $A, B$ and C. 


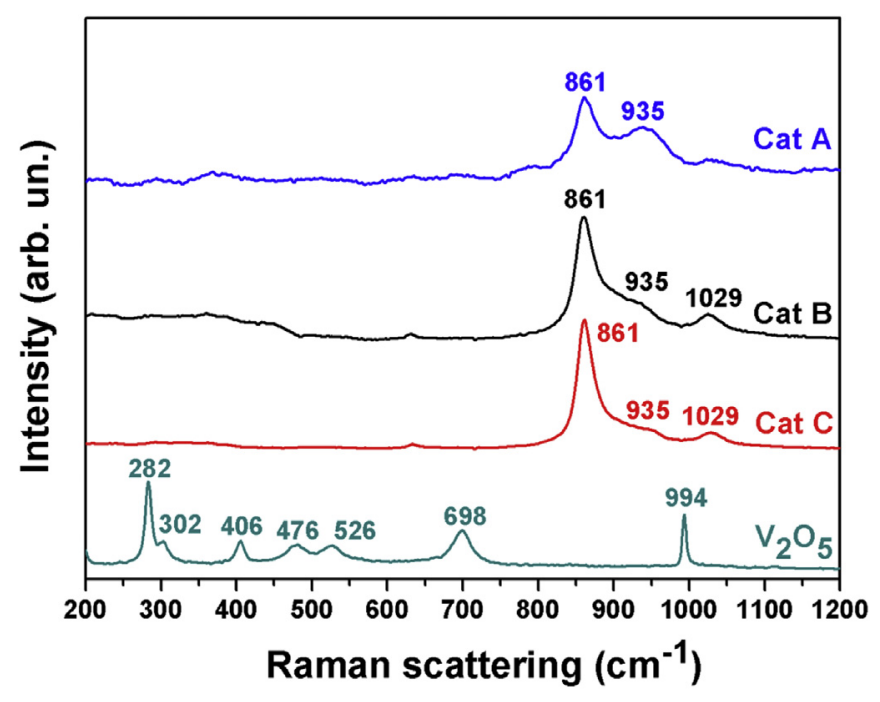

Fig. 5. Raman spectra of the catalyst A, B and C.

sites on the surfaces of the crystallites [23,28,29]. A band at $940 \mathrm{~cm}^{-1}$ was only observed for catalyst A and could similarly be ascribed to the $\mathrm{V}=\mathrm{O}$ bonds. It is important to note that no crystalline $\mathrm{V}_{2} \mathrm{O}_{5}$ phase was detected in the samples, because the fingerprint Raman bands of this phase (at 994, 701, 526, and $284 \mathrm{~cm}^{-1}$ ) were not present $[23,29,30]$.

The DR UV-Vis spectra of the vanadosilicates are shown in Fig. 6. The spectra for catalysts A, B, and C contained similar broad bands centered at around 215, 265, and $545 \mathrm{~nm}$. According to Brandão et al. [23] bands near 215 and $265 \mathrm{~nm}$ can be explained by O-to- $\mathrm{V}^{4+}$ charge transfer (CT), while the band centered at $545 \mathrm{~nm}$ is due to d$\mathrm{d}$ transitions of $\mathrm{V}^{4+}$ in octahedral $\mathrm{VO}_{6}[30]$.

The results of the TPD- $\mathrm{NH}_{3}$ measurements of the acid sites of the catalysts are presented in Fig. 7. All the materials showed very similar desorption at low $\left(180{ }^{\circ} \mathrm{C}\right)$ and medium $\left(250{ }^{\circ} \mathrm{C}\right)$ temperatures which are related to the presence of the weak and intermediary acid sites respectively. In principle, the TPD- $\mathrm{NH}_{3}$ measurements are not revealing if the desorption peaks at low temperature arise from Lewis or Bronsted acid sites. Nevertheless, is widely known that due to the electron withdrawing, the bonding between $\mathrm{NH}_{3}$ and Lewis acid sites is weaker than the bonding

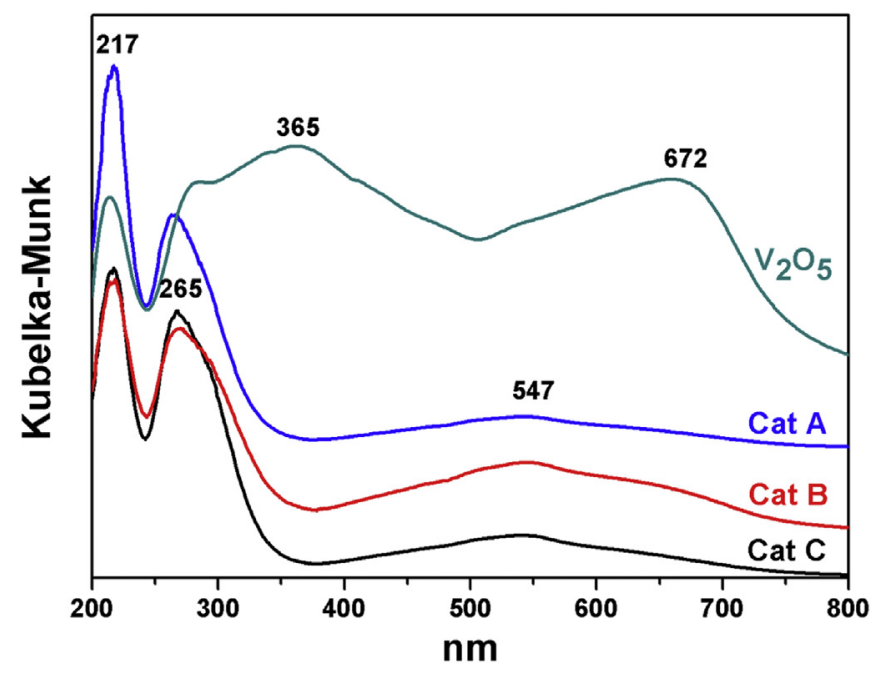

Fig. 6. Diffuse Reflectance UV-Vis spectra of catalysts.

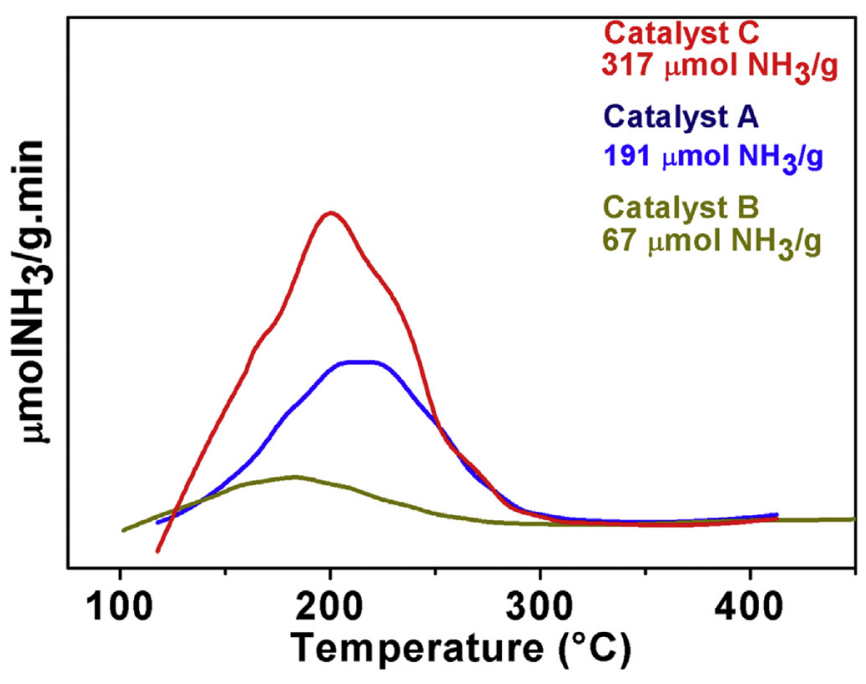

Fig. 7. Ammonia temperature programmed desorption of catalysts A, B and C.

Table 1

Glycerol conversion (\%), product selectivity (\%) and carbon balance (from 0 to 1 ) obtained for $1 \mathrm{~h}$ of reaction in the presence of vanadosilicates catalysts at $320^{\circ} \mathrm{C}$.

\begin{tabular}{|c|c|c|c|c|c|c|}
\hline Product & Cat.A & Cat.A & Cat.B & Cat.B & Cat.C & Cat.C \\
\hline$\%$ of $\mathrm{O}_{2} / \mathrm{N}_{2}$ & 20 & 100 & 20 & 100 & 20 & 100 \\
\hline Acrolein & 1.2 & 1.4 & 1.4 & 0.6 & 6.2 & 3.8 \\
\hline Acrylic acid & 15.0 & 23.4 & 8.8 & 6.0 & 18.7 & 85.4 \\
\hline Acetaldehyde & 2.8 & 2.7 & 3.4 & 1.6 & 5.4 & 3.2 \\
\hline Propanal & 4.0 & 1.0 & 5.4 & 1.5 & 4.8 & 2.3 \\
\hline Acetic acid & 0.0 & 1.6 & 0.8 & 0.6 & 2.2 & 2.5 \\
\hline 3-hydroxi-propanal & 1.1 & 0.0 & 0.5 & 0.3 & 1.5 & 0.0 \\
\hline Propanoic acid & 0.7 & 0.0 & 0.0 & 0.0 & 0.0 & 1.4 \\
\hline Carbon balance & 0.7 & 0.4 & 0.7 & 0.5 & 0.5 & 0.9 \\
\hline Conversion (\%) & 33.2 & 96.9 & 36.1 & 59.3 & 63.0 & 93.6 \\
\hline
\end{tabular}

between the $\mathrm{NH}_{3}$ and the Bronsted acid sites which are stronger due to the formation of $\mathrm{NH}_{4}{ }^{+}$. Therefore, Lewis acid sites can be broken down at temperatures lower than the Bronsted acid sites. The desorption of strong acid sites usually occurs ata temperature close or higher than $400{ }^{\circ} \mathrm{C}$ and desorption peaks observed for the vanadosilicates are below this temperature range.

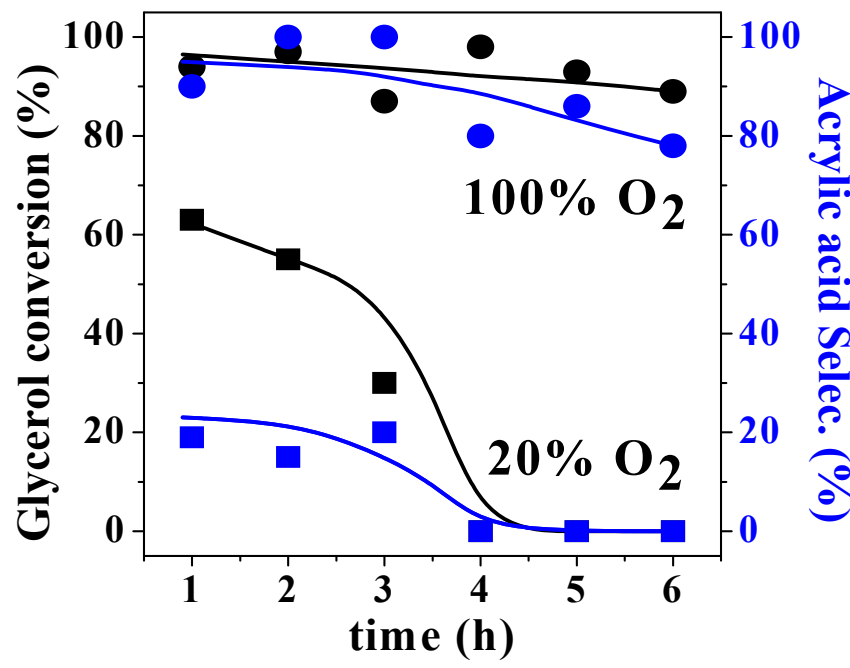

Fig. 8. Stability of the catalysts $C$ in the oxydehydration of glycerol into acrylic acid at $320^{\circ} \mathrm{C}$ and different oxygen concentrations. 
a) Dehydration reaction mechanism<smiles>C[Si](C)(C)OO[C@@H](O[Si](C)(C)O[Si](C)(C)C)[C@H](CO)O[Si](C)(C)C</smiles><smiles>C[Si](C)(C)O[Si](C)(C)O[Si](C)(C)O[Si](C)(C)C=CO</smiles><smiles>C[Si](C)(C)O[C@H](C=C[Si](C)(C)O[Si](C)(C)O[Si](C)(C)O[Si](C)(C)C)CO</smiles>

(2) keto-enol tautomerism<smiles>C[Si](C)(C)OCC(C=O)CO[Si](C)(C)O[Si](C)(C)O[Si](C)(C)O[Si](C)(C)C</smiles><smiles>C[Si](C)(C)O[Si](C)(C)O[Si](C)(C)O[Si](C)(C)O[Si](C)(C)C</smiles>

(3) second dehydration

b) Oxydation reaction mechanism

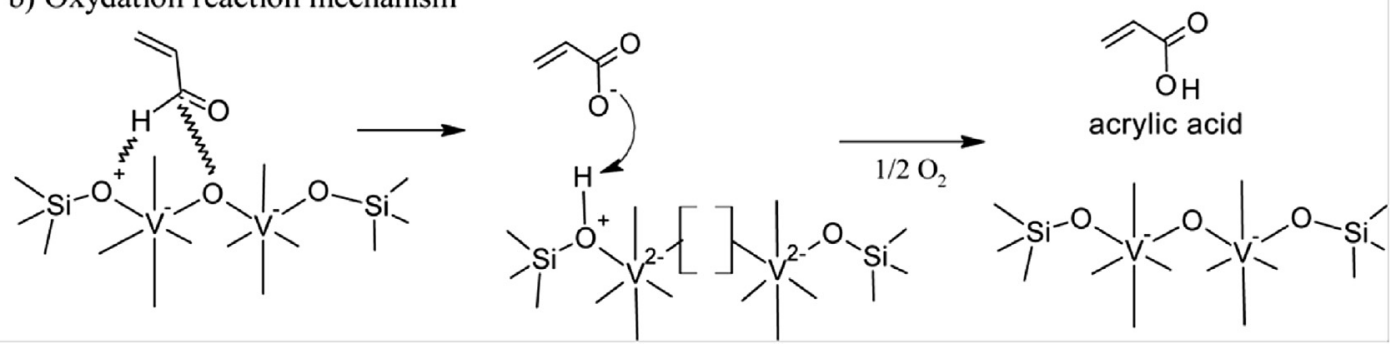

Fig. 9. (a) Conversion mechanism of glycerol into acrolein and (b) conversion mechanism of acrolein into acrylic acid.

A greater quantity of acid sites is present in the catalyst $\mathrm{C}$ (317 $\mu \mathrm{mol}$ of $\left.\mathrm{NH}_{3} \mathrm{~g}^{-1}\right)$, compared to catalysts A (191 $\mu \mathrm{mol}$ of $\left.\mathrm{NH}_{3} \mathrm{~g}^{-1}\right)$ and $\mathrm{B}\left(67 \mu \mathrm{mol}\right.$ of $\left.\mathrm{NH}_{3} \mathrm{~g}^{-1}\right)$. It has been reported previously [13] that the quantity of acid sites depends on the environment of the vanadium oxide species [13]. In the present case, the ${ }^{51} \mathrm{~V}$ MAS NMR data (Fig. 4) revealed that the vanadium environment in the catalyst varied according to the structure directing agent used in the synthesis.

\subsection{Catalytic tests}

Out of the three catalysts tested (Table 1, Fig. 8), catalyst C showed the best performance, with conversion of up to $93.6 \%$ of 
glycerol into acrylic acid (85.4\%). Other important chemicals produced in smaller amounts included acrolein (3.8\%), propanal (2.3\%), acetaldehyde (3.2\%), acetic acid (2.5\%), and propionic acid (1.4\%). Catalysts B and A were able to convert $59.3 \%$ and $96.9 \%$ of the glycerol, respectively, but the selectivities towards acrylic acid were very low (6.0\% and $23.4 \%$, respectively).

It is possible that the high activity and selectivity of catalyst $C$ was due to the unique vanadium environment, which promoted changes of the $\mathrm{V}^{5+} / \mathrm{V}^{4+}$ oxidation states during the catalytic reaction. This is a typical oxidation reaction performed by means of the Mars-van Krevelen mechanism [31]. In the first step of the process, the adsorbed reactant is oxidized by an oxygen ion present in the lattice of the vanadosilicate, followed by desorption of the product (which in this case was acrylic acid). In a second step, an oxygen molecule from the gas phase restores the fully oxidized state of the catalyst. The sharp decline in the activity of catalyst $\mathrm{C}$ in an $\mathrm{N}_{2}$-rich atmosphere was indicative of the importance of $\mathrm{O}_{2}$ for the selective conversion of glycerol, since the $\mathrm{O}_{2}$ acted to restore the oxygen vacancies of the vanadosilicates during the catalytic cycle [32-34], as well as to prevent coke formation on the actives sites [13] (Fig. 9).

The carbon balance (Table 1) was determined using the mass balance of condensed products flowing out from the reactor, without considering non-condensable gases such as $\mathrm{CO}$ and $\mathrm{CO}_{2}$ and heavy or oligomeric products that were deposited on the catalyst surface. The low carbon balances for catalysts A and B during the catalytic reaction, together with a change in catalyst color from yellow to yellow-grayish, suggested the formation of coke, which could negatively influence the selectivity to acrylic acid. Other negative factors were the formation of acetaldehyde and acetic acid (molecules with 2 carbon atoms). Hence, the $\mathrm{CO}_{2}$ produced due to carbonization of glycerol was not included in the carbon balance [22].

The almost complete carbon balance $(0.9)$ for catalyst $C$ indicated that the further oxidation of glycerol products to $\mathrm{CO}_{2}$ and $\mathrm{CO}$ in a pure oxygen atmosphere was low. However, the missing 0.1 in the carbon balance could have been due to the oxidation of coke deposited on the surface of this catalyst to more volatile compounds.

The correlation between the acid sites strength and coke formation has recently been reported in the literature $[13,22-24,35,36]$, and it was found that coke formation was strongly influenced by the presence of strong acid sites whose desorption of ammonium was close to $400{ }^{\circ} \mathrm{C}$. In this study the observed ammonia chemisorption measurements occurred at temperature lower than $400{ }^{\circ} \mathrm{C}$, which allows us to infer the vanadosilicate catalysts mainly possess weaker acid sites, therefore precluding coke formation. In addition, TGA measurements of the spent catalyst C (Supplementary Material) has revealed no weight loss corresponding to coke. These results are very consistent with those presented in the studies $[13,22]$ in which we showed that the combination of both weak acid sites and vanadium oxides are important for the suppression of coke formation in the catalyst.

The possible steps of glycerol dehydration and then oxidation of acrolein to form acrylic acid, according to the Mars-van Krevelen mechanism, are proposed based on experimental evidence that the vanadium silicate structure contains linear chains of alternating $\mathrm{V}=\mathrm{O}$ and $\mathrm{V}-\mathrm{O}$ bonds, as reported by Damin et al. [37]. These chains are orientated in two orthogonal directions and are surrounded by tetrahedral silicate units. The complete process of glycerol conversion is displayed in Fig. 9a and b. The dehydration mechanism involves the transformation of glycerol to 3-hydroxypropanal, which is subsequently dehydrated to acrolein (Fig. 9a). The acrolein formed is then converted to acrylic acid by the action of the redox sites generated by vanadium atoms in the catalyst (Fig. 9b). Hence, based on the Mars-van Krevelen mechanism [31,38], the

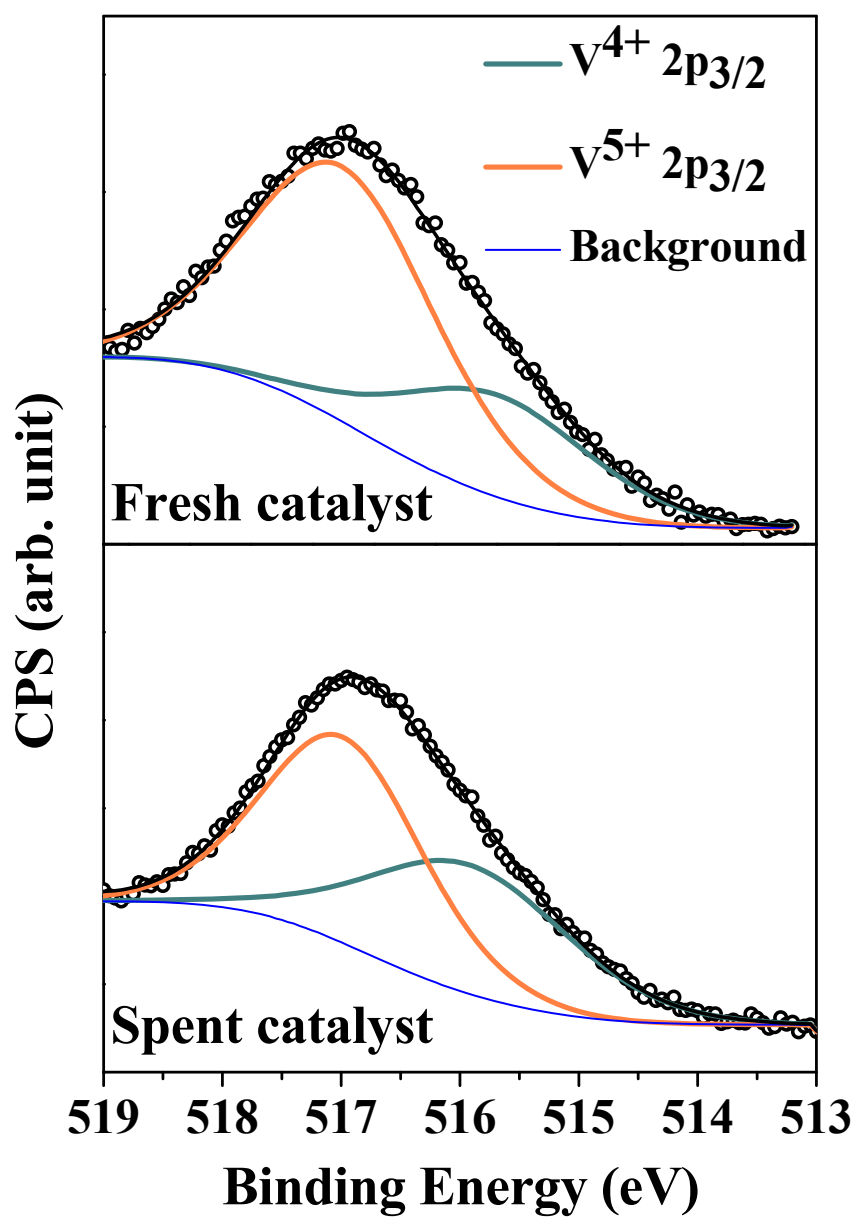

Fig. 10. XPS spectra of the catalyst $C$ before and after glycerol conversion reaction.

vanadosilicate lattice oxygen is responsible for the oxidation of acrolein to acrylic acid, and the vacancies created by the release of framework oxygen are restored by the $\mathrm{O}_{2}$-rich atmosphere of the reaction.

The XPS spectra for catalyst $\mathrm{C}$, before and after the catalytic conversion of glycerol to acrylic acid, are shown in Fig. 10. The catalytic tests indicated that the presence of both $\mathrm{V}^{4+}$ and $\mathrm{V}^{5+}$ species could have played an important role in the reactivity and the selectivity of glycerol oxidehydration to acrylic acid. The XPS results supported the proposed mechanism (Fig. 9) whereby the substrate to be oxidized, in this case acrolein, promoted the reduction of the catalyst $\left(\mathrm{V}^{5+} \rightarrow \mathrm{V}^{4+}\right)$. Changes in the oxidation number of the vanadium species $\left(\mathrm{V}^{+5}\right.$ and $\left.\mathrm{V}^{+4}\right)$ were observed by means of the changes in the $\mathrm{V} 2 \mathrm{p}_{3} / 2$ binding energy, attributed to $\mathrm{V}^{4+}$ and $\mathrm{V}^{5+}$. According to the XPS data, around $71 \%$ of $\mathrm{V}^{5+}$ and $29 \%$ of $\mathrm{V}^{4+}$ were present in catalyst $\mathrm{C}$ prior to the oxidation reaction, while after the reaction the percentage of $\mathrm{V}^{4+}$ increased from 29 to $44 \%$. This is strong experimental evidence that catalyst $C$ was

Table 2

Surface atomic composition of catalyst $\mathrm{C}$ before and after utilization in glycerol conversion reaction.

\begin{tabular}{llc}
\hline Elements & Atomic $(\%)$ & \\
\cline { 2 - 3 } & Before reaction & After reaction \\
\hline Oxygen (O 1s) & 66.0 & 68.1 \\
Vanadium (V 2p) & 3.6 & 4.2 \\
Silicon (Si 2p) & 30.5 & 27.7 \\
\hline
\end{tabular}


Table 3

Catalytic conversion of glycerol into acrolein and acrylic acid with different vanadium based heterogeneous catalysts.

\begin{tabular}{|c|c|c|c|c|c|}
\hline Catalyst & $\mathrm{T}\left({ }^{\circ} \mathrm{C}\right)$ & X glycerol (\%) & Selectivity to acrolein (\%) & Selectivity to acrylic acid (\%) & Ref. \\
\hline $\mathrm{V}-\mathrm{P}-\mathrm{O}$ & 300 & 81 & 55 & 1.0 & {$[40]$} \\
\hline $\mathrm{V}_{2} \mathrm{O}_{5}$ & 300 & 40 & 12 & 5.0 & [13] \\
\hline $\mathrm{VOHPO}_{4}$ & 300 & 100 & 43 & 8.0 & [6] \\
\hline $\mathrm{V}_{2} \mathrm{O}_{5} / \mathrm{MFI}$ & 350 & 100 & 15 & 17 & [13] \\
\hline V-Mo-oxides & 300 & 90.0 & 10 & 20 & [37] \\
\hline V-W-oxides & 300 & 100 & 0.1 & 24 & [8] \\
\hline V-W-oxides & 310 & 100 & 11 & 25 & [10] \\
\hline V-Bea & 275 & 75 & 45 & 25 & {$[12]$} \\
\hline V-W-oxides & 300 & 90 & 20 & 26 & [37] \\
\hline V-Mo-oxides & 300 & 100 & 3.0 & 26 & [8] \\
\hline $\mathrm{V}-\mathrm{Mo}-\mathrm{Te}-\mathrm{Nb}$-oxides & 300 & 99 & 2.0 & 28 & [8] \\
\hline V-SiW/HZSM-5 ${ }^{\mathrm{a}}$ & 90 & 98 & 0.8 & 32 & [14] \\
\hline V-W-Nb-oxides & 290 & 100 & 17 & 34 & [38] \\
\hline $\mathrm{SiW} / \mathrm{Al}_{2} \mathrm{O}_{3} / \mathrm{Mo}_{3} \mathrm{VOx}$ & 300 & 100 & 3.0 & 46 & [41] \\
\hline V-W-Nb-oxides & 265 & 100 & 3.0 & 50 & [11] \\
\hline $\mathrm{PO}_{4} / \mathrm{W}-\mathrm{V}-\mathrm{Nb}-\mathrm{O}$ & 285 & 100 & 0.5 & 59 & [39] \\
\hline $\mathrm{FeVO}_{4}$ & 300 & 100 & 1.0 & 76 & [7] \\
\hline Catalyst C & 320 & 93.6 & 5.3 & 89.6 & This work \\
\hline
\end{tabular}

a Liquid phase.

partially reduced during the process of oxidation of acrolein to acrylic acid. This dynamic oxidation of $\mathrm{V}^{4+}$ to $\mathrm{V}^{5+}$ was promoted by the oxygen-rich atmosphere and completed the catalytic cycle (Fig. 9). The surface composition (analysis depth $<5 \mathrm{~nm}$ ) of catalyst $C$ was obtained from the high resolution XPS spectra (Table 2). After the catalytic glycerol conversion, there was a $17 \%$ increase of vanadium in the catalyst surface, which could have been due to vanadium leaching from sites in the crystal structure to the surface of the material, possibly caused by the loss of crystallinity shown in the XRD data.

Under these experimental conditions $\left(320^{\circ} \mathrm{C}\right.$ and a high level of oxygen), vanadium atoms can be easily oxidized and reduced. Hence, since vanadium atoms were part of the framework, the change in the oxidation state could, in principle, lead to disruption of the structure. Therefore, the loss of crystallinity after the reaction (as supported by the XRD data) was in agreement with the supposition that the redox sites were the bonds between the framework oxygen atoms and the vanadium atoms.

Table 3 lists the results obtained previously for glycerol oxidehydration to acrylic acid using several different vanadium-based catalysts [39-44]. Comparison of the reported conversion and selectivity values with those obtained in the present work clearly indicates the possibility of a new catalytic route for one-step glycerol oxidehydration to acrylic acid using AM-6-like vanadosilicate catalysts.

\section{Conclusions}

Vanadosilicates isostructural to the titanosilicates ETS-10 and AM-6 were highly efficient and selective in one-step oxidehydration of glycerol to acrylic acid. Spectroscopic analyses indicated that the excellent performance of these catalysts could be ascribed to dynamic shifts between oxidized and reduced states of vanadium during the catalytic reaction according to the Mars-van Krevelen redox cycle. The findings indicate a possible new catalytic route for one-step glycerol oxidehydration to acrylic acid using this vanadosilicate family.

\section{Acknowledgments}

Financial support for this work was provided by the São Paulo State Research Foundation (FAPESP) in the form of grants to JGN (processes \#05/54703-6 and \#11/51851-5) and LM (process \#10/ 01449-3). We also thank CAPES and the National Council for
Scientific and Technological Development for financial support to JGN (grant \#07/478104-3). Prof. Michael Tsapatsis (UMass) is gratefully acknowledged for supporting and encouraging this work.

\section{Appendix A. Supplementary data}

Supplementary data related to this article can be found at http:// dx.doi.org/10.1016/j.micromeso.2016.05.014.

\section{References}

[1] T.A. Werpy, Top value added chemicals from biomass, in: J.E. Holladay (Ed.), US DOE, 2004. Technical Report.

[2] C.-H.C. Zhou, J.N. Beltramini, Y.-X. Fan, G.O.M. Lu, Chemoselective catalytic conversion of glycerol as a biorenewable source to valuable commodity chemicals, Chem Soc Rev 37 (2008) 527-549.

[3] Y.-C. Lin, Catalytic valorization of glycerol to hydrogen and syngas, Int J Hydrogen Energy 38 (2013) 2678-2700.

[4] X. Xu, J. Lin, P. Cen, Advances in the Research and development of acrylic acid production from Biomass1, Chin J Chem Eng 14 (2006) 419-427.

[5] R. Grasselli, Fundamental principles of selective heterogeneous oxidation catalysis, Top Catal 21 (2002) 79-88.

[6] F. Wang, J.-L. Dubois, W. Ueda, Catalytic dehydration of glycerol over vanadium phosphate oxides in the presence of molecular oxygen, J Catal 268 (2009) 260-267.

[7] F. Wang, J. Xu, J.-L. Dubois, W. Ueda, Catalytic oxidative dehydration of glycerol over a catalyst with iron oxide domains embedded in an iron orthovanadate phase, ChemSusChem 3 (2010) 1383-1389.

[8] J. Deleplanque, J.L. Dubois, J.F. Devaux, W. Ueda, Production of acrolein and acrylic acid through dehydration and oxydehydration of glycerol with mixed oxide catalysts, Catal Today 157 (2010) 351-358.

[9] K. Omata, S. Izumi, T. Murayama, W. Ueda, Hydrothermal synthesis of W-Nb complex metal oxides and their application to catalytic dehydration of glycerol to acrolein, Catal Today 201 (2013) 7-11.

[10] M.D. Soriano, P. Concepción, J.M.L. Nieto, F. Cavani, S. Guidetti, C. Trevisanut, Tungsten-Vanadium mixed oxides for the oxidehydration of glycerol into acrylic acid, Green Chem 13 (2011) 2954-2962.

[11] A. Chieregato, M.D. Soriano, F. Basile, G. Liosi, S. Zamora, P. Concepción, F. Cavani, J.M. López Nieto, One-pot glycerol oxidehydration to acrylic acid on multifunctional catalysts: focus on the influence of the reaction parameters in respect to the catalytic performance, Appl Catal B Environ 150-151 (2014) $37-46$.

[12] C.F.M. Pestana, A.C.O. Guerra, G.B. Ferreira, C.C. Turci, C.J.A. Mota, Oxidative dehydration of glycerol to acrylic acid over vanadium-impregnated zeolite beta, J Braz Chem Soc 24 (2013) 100-105.

[13] L.G. Possato, W.H. Cassinelli, T. Garetto, S.H. Pulcinelli, C.V. Santilli, L. Martins, One-step glycerol oxidehydration to acrylic acid on multifunctional zeolite catalysts, Appl Catal A General 492 (2015) 243-251.

[14] S. Thanasilp, J.W. Schwank, V. Meeyoo, S. Pengpanich, M. Hunsom, One-pot oxydehydration of glycerol to value-added compounds over metal-doped SiW/HZSM-5 catalysts: effect of metal type and loading, Chem Eng J 275 (2015) 113-124. 
[15] J.A. Cecilia, C. García-Sancho, J.M. Mérida-Robles, J. Santamaría-González, R. Moreno-Tost, P. Maireles-Torres, V and V-P containing Zr-SBA-15 catalysts for dehydration of glycerol to acrolein, Catal Today 254 (2015) 43-52.

[16] J. Rocha, P. Brandão, Z. Lin, M.W. Anderson, V. Alfredsson, O. Terasaki, The first large-pore vanadosilicate framework containing hexacoordinated vanadium, Angewandte Chemie, Int Ed Engl 36 (1997) 100-102.

[17] M.N. Ismail, N.D. Fraiman, D.M. Callahan Jr., G. Gursoy, E. Viveiros, O. Ozkanat, Z. Ji, R.J. Willey, J. Warzywoda, A. Sacco Jr., First unseeded hydrothermal synthesis of microporous vanadosilicate AM-6, Microporous Mesoporous Mater 120 (2009) 454-459.

[18] A.S. Paula, A. de Vasconcellos, J.A. Ellena, M. Giotto, J.G. Nery, Hydrothermal syntheses of ETS-10 like vanadosilicates using chiral organic molecules. Part I Microporous Mesoporous Mater 147 (2012) 30-46.

[19] A. Philippou, M. Naderi, J. Rocha, M. Anderson, Dehydration of t-butanol over basic ETS-10, ETAS-10 and AM-6 catalysts, Catal Lett 53 (1998) 221-224.

[20] F. Serralha, J. Lopes, F. Lemos, D. Prazeres, M. Aires-Barros, J. Rocha, J. Cabral, F. Ribeiro, Titanosilicates as supports for an enzymatic alcoholysis reaction, React Kinet Catal Lett 69 (2000) 217-222.

[21] M.J. Nash, R.F. Lobo, D.J. Doren, Photocatalytic oxidation of ethylene by ammonium exchanged ETS-10 and AM-6, Appl Catal B Environ 88 (2009) 232-239.

[22] L.G. Possato, R.N. Diniz, T. Garetto, S.H. Pulcinelli, C.V. Santilli, L. Martins, A comparative study of glycerol dehydration catalyzed by micro/mesoporous MFI zeolites, J Catal 300 (2013) 102-112.

[23] P. Brandão, A. Philippou, N. Hanif, P. Ribeiro-Claro, A. Ferreira, M.W. Anderson, J. Rocha, Synthesis and characterization of two novel large-pore crystalline vanadosilicates, Chem Mater 14 (2002) 1053-1057.

[24] N. Das, H. Eckert, H. Hu, I.E. Wachs, J.F. Walzer, F.J. Feher, Bonding states of surface vanadium(V) oxide phases on silica: structural characterization by vanadium-51 NMR and Raman spectroscopy, J Phys Chem 97 (1993) $8240-8243$.

[25] H. Eckert, I.E. Wachs, Solid-state vanadium-51 NMR structural studies on supported vanadium(V) oxide catalysts: vanadium oxide surface layers on alumina and titania supports, J Phys Chem 93 (1989) 6796-6805.

[26] T. Sen, V. Ramaswamy, S. Ganapathy, P.R. Rajamohanan, S. Sivasanker, Incorporation of vanadium in zeolite lattices: studies of the MEL (ZSM-11) system, J Phys Chem 100 (1996) 3809-3817.

[27] T. Sen, P.R. Rajamohanan, S. Ganapathy, S. Sivasanker, The nature of vanadium in vanado-silicate (MFI) molecular sieves: influence of synthesis methods, J Catal 163 (1996) 354-364.

[28] G. Deo, I.E. Wachs, Effect of additives on the structure and reactivity of the surface vanadium oxide phase in V2O5/TiO2 catalysts, J Catal 146 (1994) $335-345$.

[29] F.D. Hardcastle, I.E. Wachs, Determination of vanadium-oxygen bond distances and bond orders by Raman spectroscopy, J Phys Chem 95 (1991) 5031-5041.
[30] M. Guo, G. Li, F. Fan, Z. Feng, C. Li, Enhancement of the visible light absorption intensity of microporous vanadosilicate AM-6, Chem Commun 48 (2012) $11892-11894$.

31] P. Mars, D.W. van Krevelen, Oxidations carried out by means of vanadium oxide catalysts, Chem Eng Sci 3 (Suppl. 1) (1954) 41-59.

[32] A. Witsuthammakul, T. Sooknoi, Direct conversion of glycerol to acrylic acic via integrated dehydration-oxidation bed system, Appl Catal A Genera 413-414 (2012) 109-116.

[33] J. Tichý, Oxidation of acrolein to acrylic acid over vanadium-molybdenum oxide catalysts, Appl Catal A General 157 (1997) 363-385.

[34] L. Giebeler, P. Kampe, A. Wirth, A.H. Adams, J. Kunert, H. Fuess, H. Vogel Structural changes of vanadium-molybdenum-tungsten mixed oxide catalysts during the selective oxidation of acrolein to acrylic acid, J Mol Catal A Chem 259 (2006) 309-318.

[35] M.V. Rodrigues, C. Vignatti, T. Garetto, S.H. Pulcinelli, C.V. Santilli, L. Martins, Glycerol dehydration catalyzed by MWW zeolites and the changes in the catalyst deactivation caused by porosity modification, Appl Catal A General 495 (2015) 84-91.

[36] L.H. Vieira, K.T.G. Carvalho, E.A. Urquieta-González, S.H. Pulcinelli, C.V. Santilli, L. Martins, Effects of crystal size, acidity, and synthesis procedure on the catalytic performance of gallium and aluminum MFI zeolites in glycero dehydration, J Mol Catal A Chem.,10.1016/j.molcata.2015.12.019, [in press].

37] R.M. Yeates, M.J. Murdoch, P.D. Southon, A.C. McLaughlin, R.F. Howe, F. Bonino, S. Bordiga, A. Damin, AM-6: a microporous one-dimensional ferromagnet, Dalton Trans (2009) 8025-8032.

[38] T.V. Andrushkevich, G.Y. Popova, Mechanism of heterogeneous oxidation of acrolein to acrylic acid, Russ Chem Rev 60 (1991) 1023.

[39] J.G. Nery, A.S. Paula, L.G. Possato, L. Martins, in: U.E.P.J.d.M. Filho (Ed.), Processo de obtenção de ácido acrílico a partir do glicerol e uso de vanadosilicatos microporosos no referido processo, 2014. Brazil.

[40] L. Shen, H. Yin, A. Wang, X. Lu, C. Zhang, Gas phase oxidehydration of glycerol to acrylic acid over Mo/V and W/V oxide catalysts, Chem Eng J 244 (2014) 168-177.

[41] A. Chieregato, F. Basile, P. Concepción, S. Guidetti, G. Liosi, M.D. Soriano, C. Trevisanut, F. Cavani, J.M.L. Nieto, Glycerol oxidehydration into acrolein and acrylic acid over W-V-Nb-O bronzes with hexagonal structure, Catal Today 197 (2012) 58-65.

[42] K. Omata, K. Matsumoto, T. Murayama, W. Ueda, Direct oxidative transformation of glycerol to acrylic acid over Nb-based complex metal oxide catalysts, Catal Today 259 (1) (2016) 205-212.

43] F. Wang, J.-L. Dubois, W. Ueda, Catalytic performance of vanadium pyrophosphate oxides (VPO) in the oxidative dehydration of glycerol, Appl Catal A General 376 (2010) 25-32.

[44] L. Liu, B. Wang, Y. Du, Z. Zhong, A. Borgna, Bifunctional Mo3VOx/ H4SiW12O40/Al2O3 catalysts for one-step conversion of glycerol to acrylic acid: catalyst structural evolution and reaction pathways, Appl Catal B Environ 174-175 (2015) 1-12. 